\title{
Study on the Strategies of Enterprise Human Resource Cost Control
}

\author{
Han Yingjun, Fan Ailing, Sun Rui
}

The Hebei United University,063009

\begin{abstract}
As an important carrier of knowledge and skills, the position of human resources is irreplaceable in the business operations and development. Because human resources play important role in the enterprise to make modern businesses continue to strengthen human resources management while expand its exploration and innovation. Currently, as an important component of business costs section, the cost of human resources has been an important issue to study and learn in modern management. In this context, some strategies of enterprise human resource cost control are discussed which mainly includes movement of persons, wages,bonuses, recruitment and selection, staff training and development strategies and management strategy.

Keywords:Human Resource,cost control,control strategies.
\end{abstract}

\section{Introduction}

With the continuous development of economy, the economic structure of the modern economy transformation from production-oriented to technology service-oriented has become a trend. This change makes the rule human resources play in the enterprise production and management and national economic development become more critical. Coupled with the increasingly fierce international competition. People pay more attention to human resources.

Human resources is the sum of the ability to work in a certain area within the overall population, and it is one of the national economic resources naturally present in the human organism lives. Human resources is a scarce resource, acquisition, development and use of human resources are required to pay a high price. Especially with the development of economy, technology and management progress, the focus of competition among enterprises focus on the talent competition. In order to obtain the human resources and talents, you need a lot of investment, which is reflected in the enterprise human resource costs. With the establishment of enterprise system now, our country has established a new accounting system. Some of our industries and companies have to carry out statistical work of human resource costs, but many companies still do not have a complete human resource costs overview concept, the total cost of human resources is not made control and accounting, especially lack of cost analysis and control of human resources. In this case, it is particularly important for a reasonable cost control of the enterprise human resources.

This paper describes the following aspects of how enterprises should develop the right human resources cost control strategies. 


\section{Enterprise human resource cost control} strategies

\subsection{Policy on the movement of persons}

As to management efficiency, the moderate movement of persons within the enterprise can promote competition among employees, improve the operation efficiency of the whole organization, and have a greater advantage to enhance the vitality of enterprises. But too often, unnecessary movement of people has a negative impact on normal operation of enterprise resulting in loss of the business economy, which includes the loss of customer relationships and trade secrets, also human resources loss through investment in human resources. Next, we can take an example to look how much loss will bring when people leave the company's human resources.

Suppose that in order to obtain appropriate department head in a company,the cost of the following occurs: the acquisition costs 150000 yuan, training costs50000 yuan, the initial value of the division is in charge of 1 million. The head is expected to hold office for five years and the annual salary is 100000yuan. Once the training is completed,the base year value when the department head starts to serve the corporate is $100+15+5=120$ ten thousand yuan. While as investment in human resources, acquisition costs and development costs are amortized during the accounting period of the asset. Here uses the straight-line amortization method, the amortization of40,000 yuan per year, salary is included in the costs as use cost. The cumulative value $=$ the base year value + the annual salary for each year-amortized cost and training costs, namely:

The first annual value: $120+10-4=1.26$ million yuan;

The second year value: $120+20-4=1.36$ million yuan;

The third annual value: $120+30-4=1.46$ million yuan;

The fourth annual value: $120+40-4=1.56$ million yuan;

The fifth annual value: $120+50-4=1.66$ million yuan.

If the department head leaves office after a year, then it will result in a direct loss of 1.26 million yuan to the company's human resources, and will result in an empty post costs. Namely, due to staff turnover, indirect losses are caused for the task is not complete. If the supervisor resign, organizations can ask him to make the necessary compensation, but such compensation is not sufficient to compensate for the loss of human resources organization, but no adverse effects on the behavior of employees in service. If the director is dismissed, the corresponding businesses have to pay severance pay, so that the loss will be further expanded. Therefore, considering the effectiveness of enterprises, we should avoid unnecessary movement of persons within the enterprise.

So, how to reduce turnover of personnel within the enterprise? People leave off ice because of the low employee satisfaction enterprises, so enterprises should improve the situation in the following areas. First, to streng then planning and control, through the formulation off air and implement and make effective promotion,rewards and punishments 
and evaluation system to establish enterprise normal and necessary discipline, so that employees can see their future development. The second is to strengthen the sense of service, to create more comfortable working environment for staff, including harmonious interpersonal relationships. Third,if possible, particularly in respect of employees, pay proper care of staff out of enterprises. Fourth, during goal setting or working arrangements, expected theory can be used to make the design goal for work arrangements more advanced rationality. The five is to help every employee make their personal career development plan. The sixth is on going staffing levels of the posts based on the distribution of principle. The seventh is that based on different characteristics of employees, job rotation, job enrichment and other ways are considered in job design.

\subsection{Strategy on wages}

Companies should open how high prices to attract talented people? This is a problem related to the reasonable control of the cost.

As previously mentioned,the cost can be seen as corporate human resources services purchase price paid. According to the law of value, in a normal and mature talent market, the price shall be determined by the value of human resources and market supply. Human resources value refers to the effective ability human resources provides for organizations. Value of human resources will undoubtedly generate investment in the past and are now being carried out on human resources, so we can make it that the value is determined by the production,development, maintenance, and the subsistence value of the labor necessary, namely, namely, the economic value of a person is determined by the formation of their current physical condition and knowledge, skill level. After clearing the value of human resources, companies should establish the mechanisms determined by the Human Resources salary value, namely, the basic salary of it employee shall constitute a certain value of the project to determine the pay back comb prehensive after simple conversion.

Still take the department head above for example,assume that the initial value of the means of subsistence and healthcare investment is 600 thousand yuan,professional training investment is 400 thousand yuan.Assume the working life is 30 years, then for life, health care investment,action will take place during this period, according to 30-year conversion we shouldwithdraw20,000 yuan per year. For professional training investment, due to the need of constantly updating professional knowledge, assuming the update cycle is 10 years, the10-year payback period should be recycled40,000 yuan per year, which can determine that the basic salary of the department is $4+2=60$ thousand yuan.

The bonus is paid remuneration over labor, and it is an important part of corporate compensation system. In-house of corporate,bonuses serve as an additional reward for employees successfully complete in centive tasks, which is a kind of corporate staff recognition. The main role to play is the bonus incentives which can also in crease the income of employees, reflecting on the organization's 
recognition of employee, which can effectively motivate staff. Secondly it can play the role of improving the efficiency. The refore, a reasonable bonus plan can work to motivate employees to focus on efficiency and performance levels. Finally, it plays a stabilizing role of talent,implement bonus plans can make some staffs with organization liability and good performance increase revenue while employees feel recognized for his organization and personal accomplishment to be more loyal to companies, and continue serve for the enterprise, thus stabilizing business talent and reducing personnel

\subsection{Policy On Recruitment And Selection}

Expenses Related to the occurrence of recruitment is the acquisition cost speaking before. Employee Recruitment and selection is actually good resource reserves for present and future of enterprise development, so when recruiting we should not blindly pursue low-cost and reduce the potential for a variety of personnel requirements. The main consideration should be given when the company's future business development strategy for recruitment.

First,in the formulation of the recruitment plan, we should take into account the development of the enterprise in which the next phase of the life cycle and to maintain elasticity of human resources, to avoid blindly recruit people during business growth, and finally cause excessive staff when the business down turn to become the next dilemma liabilities.

Second, before hiring we should do the job analysis, make specific instructions for the successful completion of the work, working conditions and the necessary qualifications, so far as possible from the start of the selectedpersonnelrelativelysatisfactoryforvariou spositionswithincompanies need to avoid additional costs.

Finally, attention should be paid at the time of recruitment of talent trait test. Note Whether Employees have a long-term willingness to cooperate and respect the work of other characteristics, in order to leave measures for the future flow of unnecessary preventive. Staff'learning ability and creativity are examined to determine whether they can be comean important reserve force to meet the future needs of growing businesses

\subsection{Staff training and development strategies}

Staff training and development is actually a long-term investment carried out incorporate human resources in order to achieveits future value.The main issue that should be considered is how to improve the effectiveness of the investment.

In order to improve investment efficiency of training, companies should have a choice and carry out staff training, that is to say, to choose the right time, the right work and the right employees to be properly trained, the training content cannot be directly applied to the job performance, we cannot choose the improper people to participate in training.

Therefore, the demand for training should be an alyzed and evaluated before training.First,the training of human resources, methods, teachers, textbooks, participants, funding, and time should be system planned and arranged.Secondly,in order to improve the 
effectiveness of training, the training should be established to develop incentives and make the necessary assessment and summary of work.

\subsection{Human resource management strategy}

To effectively reduce the over all cost of human resources, we should make the company's human resource management and other sectors become a profit center,the contents of the cost assessment is mainly the occurrence of human resource costs, profits is through the test of human resources contribution of various functional departments within the enterprise, with the cost ratio to be accounted for. For the whole enterprise human resource management and cost control, enterprises can also use the strategic bidding war by comparing the same situation and the effectiveness of internal departments of the enterprise and other HR departments to compare different companies to find the most effective control of human resource costs and improve methods of human resource utilization.

\section{CONCLUSIONS}

Human resource costs control objectives of different enterprise share not the same,therefore, companies should prepare periodic human resources budget according to the situation of their own characteristics and competitors cost, make good feedback on the implementation of the budget.At the same time, we should make cost-benefit analysis, statistical analysis using a reasonable method, and make description of the overall trend and level to achieve the purpose of controlling and managing costs.

\section{References}

[1] Kong X. Discussion on the inevitable principles in human resources management[J]. China Electro Power Education. 2013(36).

[2] Zhang Y. Some studies of human resources cost theory[J]. Management \& Technology of SME. 2011(01).

[3] Liu C, et al. Robust $\mathrm{H} \infty$ Control for Satellite Attitude Control System with Uncertainties and Additive Perturbation [J]. International Journal of Science, 2014, 1(2): 1-9.

[4] Wang A, Zeng B. Management theory of human resources[M]. Changsha: National University of Defense Technology Press, 2010.

[5] Lazear. E.P. Agency, earning profile, productivity and hours restrietion[J]. American Economies Review, 1981, 71(3): 606-620.

[6] Liu C, Shi K, Wang F. Mass and mass center identification of target satellite after rendezvous and docking[C]//Intelligent Control and Automation (WCICA), 2014 11th World Congress on. IEEE, 2014: 5793-5798.

[7] Erie. G. Flamholtz. Human resource accounting: a review of theory and research[J]. Journal of Management Studies, Feb74, Vol.11. 